\title{
INHALT VON EUSEBIUS BAND II 3
}

Vorwort von Eduard Schwartz. . . . . . . . . . . . .

Berichtigungen und Nachträge . . . . . . . . . . . . . XIII

Einleitung zum griechischen Text. Von Eduard Schwartz . . . XVII

I. Handschriften, OUbersetzungen und moderne Ausgaben . . . . X XII

II. Die antiken Ausgaben der KG . . . . . . . . . . . . XLVII

III. Die Gruppen der Handschriften . . . . . . . . . . . . L LXI

1. BDM $\Sigma \boldsymbol{A}$ und ATER . . . . . . . . . . . . . . . . . . $\quad$ LXI

2. Einzelgruppen in $\operatorname{BDM} \Sigma \Lambda$. . . . . . . . . . . . . . . . . XCII

3. Einzelgruppen in ATER . . . . . . . . . . . . . . . . . . CVI

4. Die Recension (Te)ERBD . . . . . . . . . . . . . . $\quad$ CXXV

5. Durchkreuzungen der Gruppen . . . . . . . . . . . CXXVII

6. Schlußbetrachtung . . . . . . . . . . . . . . . . CXLIH

IV. Oberschriften und Kephalaia . . . . . . . . . . . . . CXLVII

V. Uber die Excerpte aus Iustin und Iosephus . . . . . . . . CLIII

VI. Orthographika . . . . . . . . . . . . . . . . . . . CLXXXVII

VII. Chronologisches . . . . . . . . . . . . . . . . . . CCXV

Einleitung zu Rufin. Von Theodor Mommsen ... . . . . . . CCLI

Verzeichnis der in der Einleitung besprochenen Stellen . . . CCLXIX-LXXII Übersichten

I. Kaiserliste . . . . . . . . . . . . . . . . . . . . 3

II. Bischofslisten

1. Rom . . . . . . . . . . . . . . . . . . . . . 6

2. Alexandrien . . . . . . . . . . . . . . . . . . 9

3. Antiochia . . . . . . . . . . . . . . . . . . . 9

4. Jerusalem . . . . . . . . . . . . . . . . . . 10

III. Die Ökonomie der Kirchengeschichte . . . . . . . . . . 11

\section{Register}

I. Biblischer Index

1. Altes Testament. . . . . . . . . . . . . . . . . 49

2. Neues Testament . . . . . . . . . . . . . . . . 52

3. Aus Rufin X. XI . . . . . . . . . . . . . . . . 60 
II. Literarischer Index

1. Aus Eusebius. . . . . . . . . . . . . . . . . . . . . 60

2. Aus Rufin X. XI . . . . . . . . . . . . . . . . . . . 83

III. Personennamen

1. Aus Eusebius. . . . . . . . . . . . . . . . . . . . . 84

2. Aus Rufin X. XI . . . . . . . . . . . . . . . . . . . 124

IV. Orts- und Völkernamen

1. Aus Eusebius. . . . . . . . . . . . . . . . . . . . . 133

2. Aus Rufin X. XI . . . . . . . . . . . . . . . . . . . 154

v. Wortregister

1. Griechische Wörter . . . . . . . . . . . . . . . . . . 158

2. Lateinische Wörter . . . . . . . . . . . . . . . . . . 208

3. Hebräische und aramäische Wörter . . . . . . . . . . . . 209

4. Syntaktischer Index . . . . . . . . . . . . . . . . 209-216 